\title{
Wireless Sensor Network Design for Landslide Warning System in IoT Architecture
}

\author{
Aghus Sofwan, Sumardi, M. Ridho, Abdul Goni, \\ Department of Electrical Engineering, \\ Diponegoro University \\ Semarang, Indonesia
}

\author{
Najib \\ Department of Geology Engineering \\ Diponegoro University \\ Semarang, Indonesia
}

\begin{abstract}
Landslide disaster is frequently happened in Indonesia, which has climate characteristic, area topography, and geological structure that make this country has many landslide potential areas. During the rainy season, the load on the slopes grows due to the increase in water content in the soil, which can lead to landslide. Landslide early warning system can be built based on geological structure and some physical environment parameters using sensors using the wireless sensor network. The communication networks with Internet technology support a substantial backbone for communication. IoT architecture can accommodate wireless sensor network for landslide early warning system. This paper describes the system uses an Arduino ATMega 2560 microcontroller to collect data from many sensors. The measured and actual physical parameters are obtained, which indicates the system succeeds in providing sensed data.
\end{abstract}

Keywords-landslide; wireless sensor network; Internet of Things;

\section{INTRODUCTION}

Landslide disaster is fair often occurred in some regions of the world. On a worldwide scale, this disaster causes up to one thousand deaths, and also destructs many building [1]. Indonesia has climate characteristic, area topography, and geological structure that make this country has many landslide potential areas. Indonesia's tropical marine-monsoon climate is known to have high average rainfall characteristics. Moreover, human population may also significantly contribute to rise of landslide occurrence. The people may deforest for a certain need without considering the nature. Rainfall is a trigger for landslides. During the rainy season, there is an increase in the load on the slopes due to the increase in water content in the soil, which eventually leads to landslide. Therefore, it is indeed that science, e.g.; geological science, electrical, and communication science; should contribute to provide a system that can predict the landslide disaster. Hence, landslide early warning system can be built based on geological structure and some physical environment parameters using sensors.

A wireless sensor network is a type of network, which is composed by nodes that perform collectively to gather information of physical parameters in real time [2] [3]. A wireless sensor network may have up to thousands sensor nodes, a sink node, and a gateway. Each node, usually, is equipped with many sensors, a microcontroller, and transceiver. The node senses, and then forward the sensed data into the communication network through a gateway. Nodes are resource-limited equipment regarding memory and computational capabilities and also energy capacity [4].

Nowadays, the communication networks with Internet technology support a significant spine for communication system, which delivers the idea of anytime and anywhere connectivity in the Internet of Things (IoT) architecture [5] [6]. This introduces a recent model of communication, which bolsters communication between machines. This machine-tomachine communication may be in another form as wireless sensor network. Furthermore, IoT architecture can accommodate wireless sensor network for any requirement.

Deployment of wireless sensor network, which is integrated with IoT is proposed in many implementations, such as in agriculture [7] [8], in air pollution solution [9], in disaster management [10], in handling forest disaster [11], and in providing green environment [12]. In [7], the authors proposed wireless sensor network for soil's condition measurement to monitor oil palm plantations regarding to agricultural meteorological practices. In [8], the authors implemented a network of sensors and connectivity, which provide application to optimize agriculture irrigation. The system considers wireless sensor network and wireless moisture sensor network as components of IoT. In [9], the authors developed low cost sensors in conjunction with wireless sensor network in gathering detailed pollution map. In [10], the authors described wireless sensor network implementation for some managing specific disasters, e.g.; earthquakes, air pollution, landslide, and healthcare. In [11], the authors proposed an architecture for disaster management in forest. The proposed architecture considers deployment many sensors in a separated area. In [12], the authors proposed implementation of expert system for green campus environment in the wireless sensor network.

This paper describes the design of wireless sensor network for landslide warning system in IoT architecture. This system uses an Arduino ATMega 2560 microcontroller to collect data from many sensors. A GSM communication modem is attached to each node as a gateway. The GSM cellular network is used to propagate the collected data to the web server. 
The rest of this paper is structured as follows. In the Section II, system architecture of the proposed system is described in detail. In next section, the results of designed system and discussions are provided. And then followed by conclusions in the last section.

\section{System ARCHITECTURE}

In this section, we describe the proposed system architecture of landslide early warning system using a wireless sensor network in the Internet of Things (IoT) architecture. The system implements machine-to-machine communication, which may not need human interaction into the system. The proposed system considers three domains, which are sensor node domain, communication domain, and user access domain, as shown in Fig. 1. At the first domain, there are many nodes, which are located in many sites. Each node consists of sensor devices as resources that provide data asset [6]. The device measures physical values such as: temperature, humidity, land movement, and soil moisture. Measured data from sensors are coordinated by a single-chip microcontroller. In IoT architecture, there are many nodes of sensors that provide many type of data. Data from the node then are sent using a gateway through the second domain, i.e. communication domain, into a data server in the user access domain. In the server, data are saved and then are used for analysis, which provides an early warning decision of landslide using expert system.

Each node consists of a coordinator and four sensors, which are temperature sensor, humidity sensor, slop sensor, and soil moisture sensor. Data comes from sensors are collected by single chip microcontroller, which is Arduino Mega 2560. Fig. 2 exposes the wiring of the node. The YL-38 sensor is used to measure soil moisture. The DHT22 sensor is utilized to sense the air humidity and temperature at around of a node. The MPU6050 sensor is equipped to detect the slop of a system which provides angular momentum.

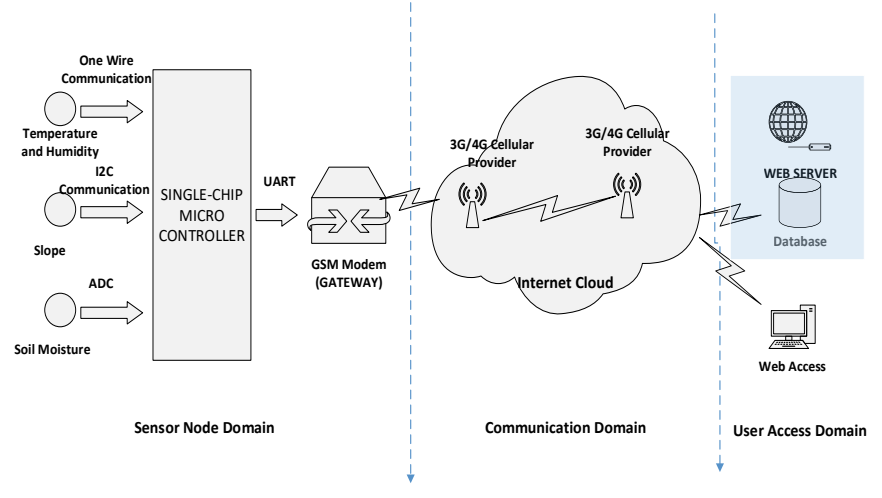

Fig. 1. Architecture of the proposed system

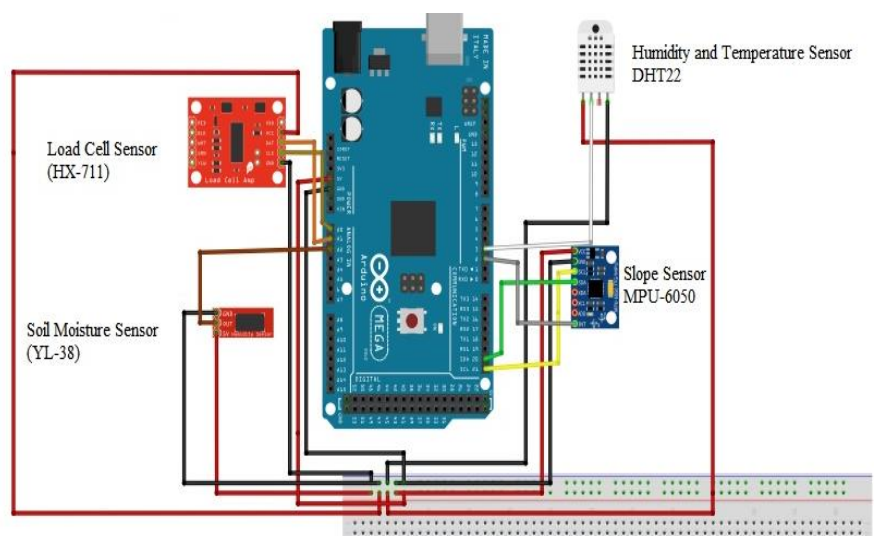

Fig. 2. Wiring scheme of a node

The nodes can be located in any place that has a landslide potential, e.g.; mountain, hill, or slope, which is not supported by wire communication. Therefore, we utilize cellular network in the communication domain due to the ubiquitous character of the node. Moreover, the cellular provider obviously provides internet services at now days. Data from a node then are transmitted using GSM modem in the gateway, e.g. from the $3 \mathrm{G} / 4 \mathrm{G}$ modem. Each node is equipped with solar cell that supplies power for its operation.

The server consists of database and web server application. Database My SQL is used to save measured data from nodes. It is composed of tables such as: recorded time and id of sensors. The apache web server application is installed in the server to provide web services. This server is connected to the Internet, so that any user or any device can access the server easily.

\section{RESULT AND DISCUSSIONS}

In this section, we provide the measurement results of devices at sensor node domain. In order to examine the device is working properly, we provide two types of data value, which are measured value and actual value. The former value is obtained from the sensor device, while the latter value is acquired from measurement using instrument. The wireless sensor network system was tested several times through many sensors, i.e.; slope, temperature, humidity, and soil moisture sensors.

Fig. 3 shows the measurement results of the slope sensor MPU 6050 which are obtained for nine hours. The measured angle and the actual angle are not exactly similar, but are close to similar. The average difference of the measured and the actual one during experiment duration has value of 1.251 degree. This indicates that the slope sensor is working properly.

Fig. 4 exposes the measurement results of Sensor DHT22, which provides measured temperature (blue line without dot markers). The actual temperature is plotted with orange line with dot markers. The figure shows difference values between both lines. The average difference value is calculated, which yields the value of $0.174{ }^{\circ} \mathrm{C}$. Therefore, we consider that the temperature sensor has been working properly. 


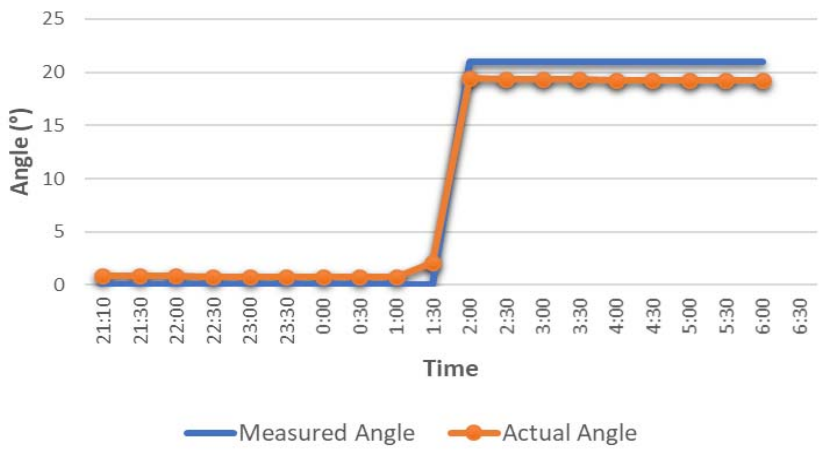

Fig. 3. Angle measurement results of slope sensor compared to actual angle result

The sensor DHT22 also can perform humidity measurement. Fig. 5 shows the measured humidity values of the sensor, which are drawn with the blue line. In addition, the actual humidity values, which are measured with hygrometer, are plotted in this figure. We can see that the both data are not exactly the same. We obtain the average difference of both has value of $4.422 \%$. This phenomenon may rise because of imperfect calibration.

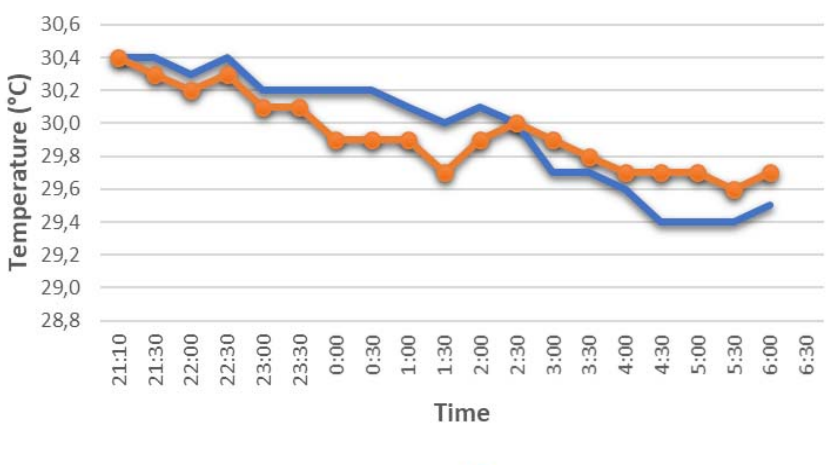

Measured Temperature $\quad$ Actual Temperature

Fig. 4. Temperature measurement of sensor which is compared to actual temperature using thermometer.

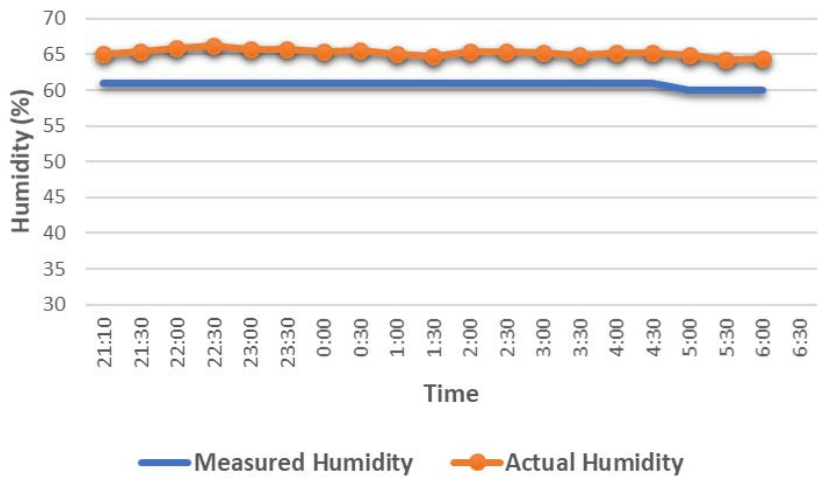

Fig. 5. Humidity measurement of sensor which is compared to actual humidity using hygrometer.

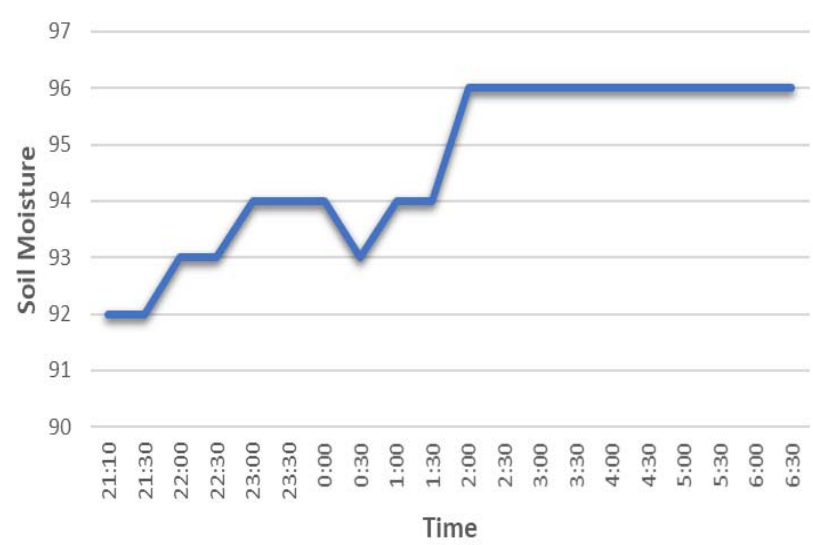

Fig. 6. Soil moisture measurement provided by YL-38.

Fig. 6 shows the measurement of soil moisture sensor (YL38) which has been calibrated. The values show changes the percentage of moisture. The values rise because of the water rain pour into the soil during experiment.

\section{CONCLUSSION}

A wireless sensor network, which measures many physical parameters that leads landslide disaster has been successfully developed. The node consists of slope sensor, humidity sensor, temperature sensor, and soil moisture sensor. The measured data which referred to the sensed data were compared to the actual data. The sensed data are transmitted into the Internet cloud through a GSM communication modem.

\section{ACKNOWLEDGMENT}

This work was supported by "Penelitian Unggulan Perguruan Tinggi Undip 2017" research grant in the fiscal year 2017.

\section{REFERENCES}

[1] R. F. Romdhane, Y. Lami, D. Genon-Catalot, N. Fourty, A. Lagrèze, D. Jongmans, et al., "Wireless sensors network for landslides prevention," in 2017 IEEE International Conference on Computational Intelligence and Virtual Environments for Measurement Systems and Applications (CIVEMSA), 2017, pp. 222-227.

[2] I. F. Akyildiz, S. Weilian, Y. Sankarasubramaniam, and E. Cayirci, "A survey on sensor networks," IEEE Communications Magazine, vol. 40, pp. 102-114, 2002.

[3] Z. Jun and J. Abbas, "Introduction to Wireless Sensor Networks," in Wireless Sensor Networks:A Networking Perspective, ed: Wiley-IEEE Press, 2009, pp. 1-18.

[4] J. Xu, G. Yang, Z. Chen, and Q. Wang, "A survey on the privacypreserving data aggregation in wireless sensor networks," Communications, China, vol. 12, pp. 162-180, 2015.

[5] A. Ali, W. Hamouda, and M. Uysal, "Next generation M2M cellular networks: challenges and practical considerations," IEEE Communications Magazine, vol. 53, pp. 18-24, 2015.

[6] J. Holler, V. Tsiatsis, C. Mulligan, S. Karnouskos, S. Avesand, and D. Boyle, From Machine-to-Machine to the Internet of Things vol. First. Oxford: Elsevier Ltd, 2014. 
[7] M. Culman, J. M. T. Portocarrero, C. D. Guerrero, C. Bayona, J. L. Torres, and C. M. d. Farias, "PalmNET: An open-source wireless sensor network for oil palm plantations," in 2017 IEEE 14th International Conference on Networking, Sensing and Control (ICNSC), 2017, pp. 783-788.

[8] I. Mat, M. R. M. Kassim, A. N. Harun, and I. M. Yusoff, "IoT in Precision Agriculture applications using Wireless Moisture Sensor Network," in 2016 IEEE Conference on Open Systems (ICOS), 2016, pp. 24-29.

[9] B. Bathiya, S. Srivastava, and B. Mishra, "Air pollution monitoring using wireless sensor network," in 2016 IEEE International WIE Conference on Electrical and Computer Engineering (WIECON-ECE), 2016, pp. 112-117.
[10] I. Benkhelifa, N. Nouali-Taboudjemat, and S. Moussaoui, "Disaster Management Projects Using Wireless Sensor Networks: An Overview," in 2014 28th International Conference on Advanced Information Networking and Applications Workshops, 2014, pp. 605-610.

[11] A. S. Bhosle and L. M. Gavhane, "Forest disaster management with wireless sensor network," in 2016 International Conference on Electrical, Electronics, and Optimization Techniques (ICEEOT), 2016, pp. 287-289.

[12] Sumardi, O. D. Nurhayati, M. N. Prasetyo, and E. D. Widianto, "Expert system for campus environment indexing in wireless sensor network," in 2015 2nd International Conference on Information Technology, Computer, and Electrical Engineering (ICITACEE), 2015, pp. 183-186. 